
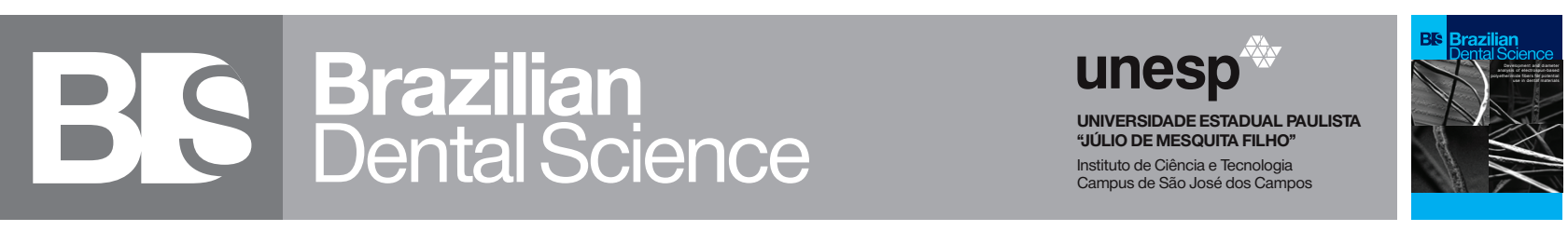

\title{
Management of Internal Derangement of Temporomandibular Joint Disc Displacement with Reduction Using Two Different Lines of Treatment
}

Manejo do Desarranjo Interno do Deslocamento de Disco Temporomandibular com Redução Utilizando Dois Tipos Diferentes de Tratamento

Mohamed Ahmed HELAL ${ }^{1}$, Shoroog Hassan AGOU ${ }^{2}$, AMR BAYOUMI ${ }^{3}$, Ahmad Y. IMAM ${ }^{4}$, Ali Habiballah HASSAN 5

1 - Department of Removable Prosthodontics, Faculty of Dentistry, Al-Azhar University (Boys Branch), Cairo, Egypt.

2 - Department of Orthodontics, Faculty of Dentistry, King Abdulaziz University, Jeddah, Saudi Arabia.

3 - Department of Oral and Maxillofacial Surgery, Faculty of Dentistry, King Abdulaziz University, Jeddah, Saudi Arabia \& Alexandria University, Alexandria, Egypt.

4 - Department of Oral and Maxillofacial Prosthodontics, Faculty of Dentistry, King Abdulaziz University, Jeddah, Saudi Arabia.

5 - Department of Orthodontics, Faculty of Dentistry, King Abdulaziz University, Jeddah, Saudi Arabia.

\section{ABSTRACT}

Objetive: This study was to compare the effectiveness of arthrocentesis versus the insertion of anterior repositioning splint (ARS) in improving the mandibular range of motion (MRM) for patients with the temporomandibular joint (TMJ) anterior disc displacement with reduction (ADDwR). Methods: 36 patients diagnosed as ADDwR were recruited and divided randomly into two groups. The first group (G1) was treated by arthrocentesis, and the second (G2) was treated using ARS. All patients were reexamined after six months. Results: Except that for protrusive movement, there were significant differences between the two groups for the percentage changes of the MRM as measured by the amount of pain free opening, unassisted opening, maximum assisted opening, right lateral and left lateral movements ( $\mathrm{p}<0.05)$. Conclusion: Within the context of the current study, the non-invasive, lower cost ARS, provided better results in improving the MRM when managing ADDwR cases.

\section{KEYWORDS}

Arthrocentesis; Anterior repositioning splint; TMD; Internal derangement; Anterior disc displacement; Mandibular range of motion.

\section{RESUMO}

Objetivo: O presente estudo comparou a eficácia da Artrocentese em relação à inserção da Placa Reposicionadora Anterior (PRA) na melhoria da Amplitude de Movimento Mandibular (AMM) para pacientes que apresentam Deslocamento de Disco Anterior com Redução (DDAcR) da Articulação Temporomandibular (ATM). Método: 36 pacientes diagnosticados como DDAcR foram recrutados e divididos aleatoriamente em dois grupos. O primeiro grupo (G1) foi tratado através da Artrocentese e o segundo (G2), tratado com a PRA. Todos os pacientes foram reexaminados após seis meses. Resultados: Com exceção do movimento protrusivo, houve diferenças significativas entre os dois grupos para as mudanças percentuais das medidas de AMM pela quantidade de abertura sem dor, abertura sem assistência, abertura máxima com assistência, movimentos laterais direitos e laterais esquerdos ( $p<0,05)$. Conclusão: Dentro do contexto do estudo atual, a PRA, não invasiva e de menor custo, proporcionou melhores resultados na melhoria da AMM no gerenciamento de casos de DDAcR.

\section{PALAVRAS-CHAVE}

Artrocentese; Placa reposicionadora anterior; DTM; Desarranjo interno; Deslocamento de disco anterior; Amplitudade de movimento mandibular. 


\section{INTRODUCTION}

A merican Academy of Orofacial Pain, temporomandibular disorder (TMD) can be defined as a collection of disorders linking the masticatory muscles, the temporomandibular joint (TMJ), and the related structures. The common TMJ illnesses are associated with pain and intra-articular complaints. Temporomandibular disorders" (TMDs) is a combined term for situations that include pain and /or dysfunction of the temporomandibular joint (TMJ), and the associated structures. Probably $3-10 \%$ of men and $8-15 \%$ of women presently suffering from TMD $[1,2]$.

The prevalence of TMD was reported to be 40-60 \% in epidemiologic studies, and it is more prevelantin females, with a peak incidence at 20 to 40 years of age $[3,4]$. TMD is one of the most common of orofacial pain. The most common disease entities of TMD include myofascial pain, internal derangement (ID) and degenerative arthritis [5].

Internal Derangement (ID) is considered one of the most common problems affecting TMJ, which includes the abnormal relationship of the articular disc as related to the mandibular condyle, the fossa, and the articular eminence [6]. It can be defined as a disruption within the internal aspects of the TMJ in which there is a displacement of the disc from its normal functional relationship with the mandibular condyle and the articular portion of the temporal bone [7]. The definition of ID of TMJ has largely been deferred to soft tissue pathophysiology models, with little agreement on other structural contributions to symptoms or to diagnostic value [8]. Understanding the biomechanics of temporomandibular joint (TMJ) is very essential to provide proper management for temporomandibular joint disorder (TMD). ID involves the actual joint apparatus, it usually presents with forward displacement of the articular disc overlying the condyle of the TMJ.
Anterior disc displacement (ADD) is commonly seen among TMD patients [9]. ADD is one of the most frequent TMJ disorders which often results in clicking, joint pain, a limited range of motion and masticatory difficulties. Disc repositioning is a common procedure for patients with ADD to eliminate the mechanical interference, to relief the pain, and to improve the range of motion [10]. The two common clinical forms of ID are anterior disc displacement with reduction (ADDwR) and without reduction (DDwoR) [11].

ADDwo R is commonly seen in TMD. It is a clinical condition where the disc is dislocated, most frequently anteromedially, from the condyle and does not return to normal position with condylar movement. However the ADDwR is a subgroup of ID, in which the articular disc has slipped forward and mouth opening is accompanied by a clicking sound at any stage of opening. Also the ADDwR may be associated with intermittent locking [3,12]. Barkin and Weinberg [13] added that "one of the clinical hallmark of ADDwR is limited mouth opening, that usually accompanied by deviation of the mandible to the involved side, until a pop or click (reduction) occurs."

Almost $5 \%$ to $10 \%$ of patients need treatment for TMD, further $40 \%$ of patients has natural resolution of indications. In one followup published article, $50 \%$ to $90 \%$ of patients got relief from pain relief after conventional therapy. A multidisciplinary approach is fruitful for managing of TMD [14], the aim of these surgical and non-surgical interventions is to restore a correct disc condylar relationship. Non-surgical treatment options include; splint therapy and physical therapy of the patient $[3,11]$.

Splint therapy, in general, is claimed to be useful for the management of patients suffering from ADDwR, the goals of this splint therapy are to correct the relationship between the glenoid fossa, articular disc and condyle, decrease joint 
pain and sounds, improve jaw function, eliminate any mechanical interference and recapture the displaced disc, the anterior repositioning splint (ARS), in specific, is used to treat ADDwR and DDwoR [15]. However, some authors argued that there is no assurance that the articular disc is recaptured by insertion of the ARS $[16,17]$.

As per Meta Analysis done by M. AlBaghdadi, twenty studies involving 1,305 patients were included. Data analysis involved 21 comparisons between a variety of interventions, either between interventions, or between intervention and placebo or no intervention. Meta-analysis on homogenous groups was conducted in 4 comparisons. In most comparisons made, there were no statistically significant differences between interventions relative to primary outcomes at short- or longterm follow-up ( $\mathrm{p}>0.05$ ) [18].

Arthrocentesis, on the other hand, is used for internal TMJ disorder cases not responding to conservative clinical treatment. It is indicated for patients with anterior disc displacement with and without reduction; for disc adhesions, for early adhesiveness next to the fossa and/ or the upper aspect of the articular tubercle, with mouth opening limitation; for cases of synovitis/capsulitis; as palliation for acute degenerative rheumatoid arthritis; patients with painful joint noises occurring during mouth opening and/or closing and for hemarthrosis due to recent trauma, where there is joint aspiration and lavage, which may provide more comfort to patient. Some investigators reported that arthrocentesis, restricted jaw opening in patients with no significant prior history of TMJ problems [19].

There is a controversy in the literature [20-32] regarding the effectiveness of the arthrocentesis and ARS in the management of ADD cases, particularly, when its effect on the mandibular range of motion is assessed. Further, data regarding the effect of these treatment modalities on the MRM in cases of ADDwR are limited. Therefore, the aim of this study was to compare the effectiveness of arthrocentesis versus the insertion of ARS in improving the MRM for patients with ADDwR. The null hypothesis was that there will be no difference between the arthrocentesis and insertion of ARS in improving the MRM in cases with ADDwR.

\section{MATERIAL AND METHODS}

Patients attending the oral and maxillofacial surgery clinic at the Department of Oral and Maxillofacial Surgery, Faculty of Dentistry, King Abdulaziz University, were recruited over a period of two years. All patients diagnosed to have unilateral ADDwR (with or without intermittent locking) using Research Diagnostic Criteria for Temporomandibular Disorders clinical protocol Axis I (RDC/TMD: Axis I) and MRI, and who had a minimum of 20 teeth, were asked to participate in the study $[10,26]$. All subjects were free from having other RDC/TMD Axis I diagnosis, such as ADDwoR, myofascial pain, history of TMJ treatment or surgery, history of jaw or facial trauma, systemic diseases or symptoms of symptomatic disease that possibly affecting masticatory system as rheumatic arthritis and epilepsy. Ethical approval was obtained from the institutional ethical review committee. Signed written consent forms were obtained from all subjects before conducting any procedures.

Subjects were randomly assigned to two groups: 12 females and 6 males each. The first group (G1) was treated by arthrocentesis, and the second (G2) was treated using ARS. Patients were informed about both treatment methods and were gave an option to change the treatment modality if they elect to do so, but none of them opted the option of change.

To evaluate the MRM of each case; the vertical jaw opening (pain free opening, 
maximum unassisted opening, and maximum assisted opening), as well as right and left lateral and protrusive jaw movements were evaluated (Table 1). These were measured for each patient before treatment (T1) and six months after treatment (T2) [28].

Table I - The different mandibular movements that were evaluated in this study

\begin{tabular}{|c|c|}
\hline Movement & Method of measurement \\
\hline $\begin{array}{l}\text { The maximal mouth ope- } \\
\text { ning: pain free opening. }\end{array}$ & $\begin{array}{l}\text { - Each patient was asked to open his/her mouth as } \\
\text { wide as he/she can without felling any pain.[12] } \\
\text { - It was measured between the edges of the upper } \\
\text { and lower right central incisors by using modified } \\
\text { caliper[[12,30] }\end{array}$ \\
\hline $\begin{array}{l}\text { The maximal mouth ope- } \\
\text { ning: maximum unassisted } \\
\text { opening. }\end{array}$ & $\begin{array}{l}\text { - Each patient was asked to open his/her mouth as } \\
\text { wide as he/she can even it is painful.[12] } \\
\text { - It was measured between the edges of the upper } \\
\text { and lower right central incisors.[27] }\end{array}$ \\
\hline $\begin{array}{c}\text { The maximal mouth ope- } \\
\text { ning:maximum assisted } \\
\text { opening. }\end{array}$ & $\begin{array}{l}\text { - Permission was obtained from each patient to } \\
\text { stretch his/her mouth further, the mouth open of the } \\
\text { patient was pushed further using moderate pressure. } \\
\text { Also the patient was informed that if he/she wants } \\
\text { the assessor to stop, to raise his/her hand.[12] } \\
\text { - It was measured between the edges of the upper } \\
\text { and lower right central incisors.[30] }\end{array}$ \\
\hline $\begin{array}{l}\text { The right lateral jaw } \\
\text { movement }\end{array}$ & $\begin{array}{l}\text { - Each patient was asked to open slightly, and to } \\
\text { move his/her jaw as far as he/she can to the right.[12] } \\
\text { - It was considered as the horizontal distance between } \\
\text { the maxillary reference midline to the mandibular } \\
\text { reference midline during right excursions.[12,30] }\end{array}$ \\
\hline $\begin{array}{c}\text { The left lateral jaw mo- } \\
\text { vement }\end{array}$ & $\begin{array}{l}\text { - Each patient was asked to open slightly, and to } \\
\text { move his/her jaw as far as he/she can to the left.[12] } \\
\text { - It was considered as the horizontal distance be- } \\
\text { tween the maxillary reference midline to the mandi- } \\
\text { bular reference midline during left excursions.[10,27] }\end{array}$ \\
\hline The protrusive movement & $\begin{array}{l}\text { - Each patient was asked to open slightly, and to } \\
\text { move his/her jaw as far as he/she can forward, even } \\
\text { it is painful. [12] } \\
\text { - It was measured from the buccal surface of the } \\
\text { mandibular central incisor tooth to the buccal surface } \\
\text { of maxillary central incisor tooth when the mandible } \\
\text { is in the maximum protruded position.[12,30] }\end{array}$ \\
\hline
\end{tabular}

The surgical (arthrocentesis) procedure was carried out as follows: The operation site was sterilized then Lidocaine $2 \%$ with 1:100,000 epinephrine was injected subcutaneously and around TMJ capsule. After that two 19-gauge needles were inserted to the joint (for inlet and exit the fluid during the TMJ arthrocentesis). Finally, the joint was lavaged with lactated Ringer's solution. Then needles were removed after arthrocentesis of the TMJ.
The maxillary ARS was constructed to keep the mandible in the anterior position [6] using $2 \mathrm{~mm}$ polyvinyl sheet (Clear advantage series I, Thermal forming splint/copolyester, Ortho Technology, USA) and cold curing acrylic resin (Hygienic orthodontic resin, Ohio, USA) (Figure 1). Patients were asked to wear the splints at least 12 hours/day for 6 months [23] (Figure 2). No medication (muscle relaxants, analgesics or anti-inflammatory agents) were prescribed to the patients.

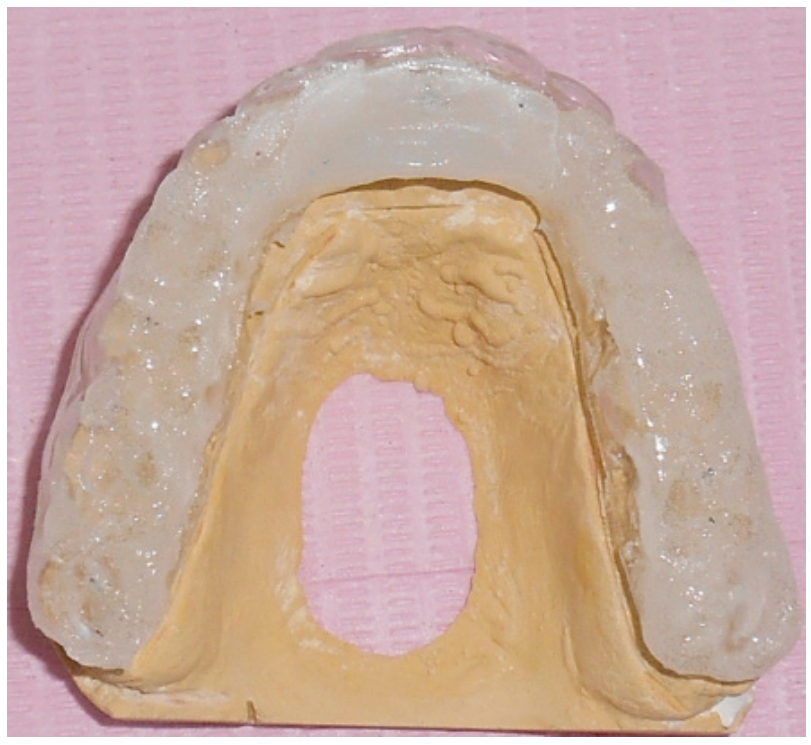

Figure 1 - The anterior repositioning splint.

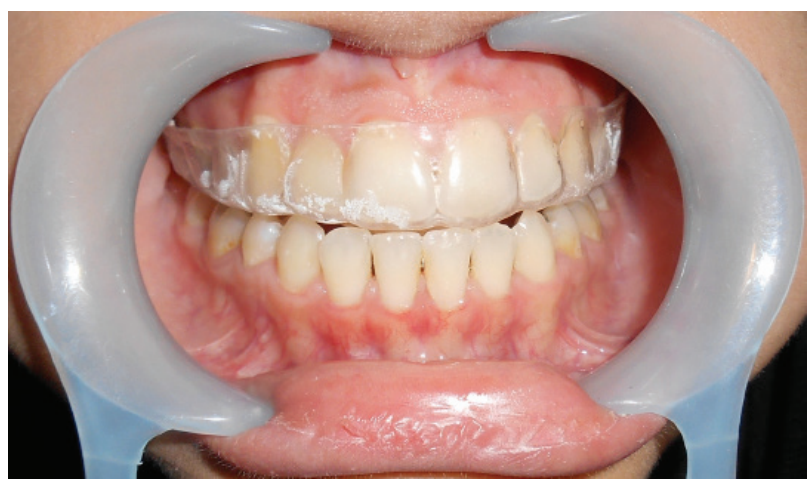

Figure 2 - The anterior repositioning splint was inserted inside the patient mouth. 
All measurements were independently obtained twice by two independent assessors. Pearson's correlation (PC) coefficients (at 95\% confidence interval) were carried out to determine the reliability between the first and second measurements of assessor 2 (test-retest reliability). The rating of the two independent assessors was recorded, and calculated using the Intra-class Correlation Coefficient (ICC), to determine the level of inter-observer reliability.

Patients of both groups were assessed at the follow-up visit, for the presence of TMJ discomfort, tooth intrusion, tooth loosening, or sensitivity on biting.

The data were collected and subjected to statistical analysis by SPSS ver.20, $\mathrm{t}$ test was used to study the effect of the arthrocentesis on the MRM of G1, and the effect of the ARS on the MRM of G2. The percentage changes were calculated for the effect of arthrocentesis on G1 and the effect of ARS on G2, and then the data were analyzed by student's t test, to compare the mean change and the percentage changes between G1 and G2.

\section{RESULTS}

Thirty-six patients (24 females and 12 males), with an age range of 20 to 44 were recruited. PC coefficient (test-retest reliability) was 0.98 ( $p<0.01$ ), and the average measure ICC index showed excellent reproducibility between the two independent assessors (ICC $0.96, \mathrm{p}<0.01$ ). These results indicated that the accuracy of measurements is more than sufficient to be used for statistical analysis.

Tables II and III show the effect of arthrocentesis and ARS on the mandibular range of motion for GI and G2. Statistically, in each line of treatment for each group, paired t test showed significant differences between before and after treatment for different movements of the MRM of the ADDwR cases at 95\% confidence level $(\mathrm{p} \leq 0.05)$.
Table II - The effectiveness of Arthrocentesis on the different movements of the MRM (mm) for Gl

\begin{tabular}{|cccccc}
\hline Treatment & Movement & $\begin{array}{c}\text { Mean } \pm \text { SD } \\
\text { Before } \\
\text { treatment }\end{array}$ & $\begin{array}{c}\text { After treat- } \\
\text { ment }\end{array}$ & $\boldsymbol{t}$ & P \\
\hline $\begin{array}{c}\text { Arthrocen- } \\
\text { tesis }\end{array}$ & $\begin{array}{c}\text { Pain free verti- } \\
\text { cal opening }\end{array}$ & $38.50 \pm 4.85$ & $41.83 \pm 5.25$ & 9.46 & $p<0.00001^{*}$ \\
$\begin{array}{c}\text { Arthrocen- } \\
\text { tesis }\end{array}$ & $\begin{array}{c}\text { Maximum } \\
\text { unassisted } \\
\text { open }\end{array}$ & $41.00 \pm 5.00$ & $44.88 \pm 5.23$ & 13.40 & $p<0.00001^{*}$ \\
\hline $\begin{array}{c}\text { Arthrocen- } \\
\text { tesis }\end{array}$ & $\begin{array}{c}\text { Maximum } \\
\text { assisted open }\end{array}$ & $42.77 \pm 4.78$ & $47.44 \pm 4.91$ & 14.00 & $p<0.00001^{*}$ \\
$\begin{array}{c}\text { Arthrocen- } \\
\text { tesis }\end{array}$ & Right Lateral & $6.55 \pm 1.94$ & $9.22 \pm 1.39$ & 7.20 & $p<0.00001^{*}$ \\
\hline $\begin{array}{c}\text { Arthrocen- } \\
\text { tesis }\end{array}$ & Left Lateral & $6.55 \pm 1.50$ & $8.72 \pm 1.27$ & 7.36 & $p<0.00001^{*}$ \\
\hline $\begin{array}{c}\text { Arthrocen- } \\
\text { tesis }\end{array}$ & Protrusive & $1.88 \pm 0.76$ & $3.38 \pm 1.03$ & 10.29 & $p<0.00001^{*}$
\end{tabular}

*Statistically significant difference

Table III - The effectiveness of ARS on the different movements of the MRM ( $\mathrm{mm})$ for Gll

\begin{tabular}{|c|c|c|c|c|c|}
\hline \multirow[b]{2}{*}{ Treatment } & \multirow{2}{*}{$\begin{array}{l}\text { Movement } \\
\text { Direction }\end{array}$} & \multicolumn{2}{|c|}{ Mean and SD \pm} & \multirow[b]{2}{*}{$t$} & \multirow[b]{2}{*}{$\mathbf{P}$} \\
\hline & & $\begin{array}{c}\text { Before } \\
\text { treatment }\end{array}$ & $\begin{array}{l}\text { After treat- } \\
\text { ment }\end{array}$ & & \\
\hline ARS & $\begin{array}{l}\text { Pain free verti- } \\
\text { cal opening }\end{array}$ & $33.61 \pm 1.97$ & $43.55 \pm 6.40$ & 8.05 & $p<0.00001^{\star}$ \\
\hline ARS & $\begin{array}{l}\text { Maximum } \\
\text { unassisted } \\
\text { open }\end{array}$ & $37.94 \pm 5.86$ & $48.61 \pm 6.91$ & 10.36 & $p<0.00001^{*}$ \\
\hline ARS & $\begin{array}{l}\text { Maximum } \\
\text { assisted open }\end{array}$ & $41.16 \pm 6.19$ & $53.38 \pm 6.44$ & 10.40 & $p<0.00001^{*}$ \\
\hline ARS & Right Lateral & $6.61 \pm 2.90$ & $10.88 \pm 3.19$ & 21.96 & $p<0.00001^{*}$ \\
\hline ARS & Left Lateral & $5.66 \pm 2.17$ & $8.88 \pm 1.52$ & 9.25 & $p<0.00001^{*}$ \\
\hline ARS & Protrusive & $1.77 \pm 0.73$ & $3.5 \pm 0.70$ & 12.718 & $p<0.00001^{*}$ \\
\hline
\end{tabular}

*Statistically significant difference

Table IV shows the pairwise comparisons between the mean change of the different movements of MRM of ADDwR cases by the effectiveness of Arthrocentesis (G1) and ARS (G2). Statistically, the pairwise comparisons using student's $t$ test showed significant differences between G1 and G2 for the mean changes of MRM movements (free pain opening, unassisted opening, maximum assisted opening, right lateral movement, and left lateral movement) except that for protrusive movement at 95\% confidence level ( $\mathrm{p} \leq 0.05$ ). Also, the pairwise comparisons using student's $t$ test showed significant differences between G1 and G2 for the percentage changes of the 
most movements of MRM (free pain opening, unassisted opening, maximum assisted opening, the right lateral movement, and left lateral movement) except that for protrusive movement at 95\% confidence level ( $\mathrm{p} \leq 0.05$ ), table V. Complications or side effects of both line of treatment either arthrocentesis or ARS (TMJ discomfort, tooth intrusion, tooth loosening, or sensitivity on biting) were not present in any of the cases of this study.

Table IV - Pairwise comparison between the mean changes of the different movements of the MRM $(\mathrm{mm})$ of ADDwR cases of $\mathrm{G} 1$ and $\mathrm{G} 2$

\begin{tabular}{|ccccc|}
\hline Movement & \multicolumn{2}{c}{ Mean change } & \multicolumn{2}{c|}{ Student's $t$ test } \\
& ARS & $\begin{array}{c}\text { Arthrocen- } \\
\text { tesis }\end{array}$ & $\boldsymbol{t}$ & P \\
\hline Free Pain opening & $9.94 \pm 5.24$ & $3.33 \pm 1.49$ & 5.14 & $\mathrm{p}<0.00001^{\star}$ \\
\hline Maximum unassisted opening & $10.66 \pm 4.36$ & $3.88 \pm 1.23$ & 6.33 & $\mathrm{p}<0.00001^{*}$ \\
\hline Maximum assisted opening & $12.22 \pm 4.98$ & $4.66 \pm 1.41$ & 6.18 & $\mathrm{p}<0.00001^{*}$ \\
\hline Right Lateral & $4.27 \pm 0.82$ & $2.66 \pm 1.57$ & 3.85 & 0.00029 \\
\hline LeftLateral & $3.22 \pm 1.47$ & $2.16 \pm 1.24$ & 2.31 & 0.013 \\
\hline Protrusive & $1.72 \pm 0.57$ & $1.5 \pm 0.62$ & 1.11 & 0.136 \\
\hline
\end{tabular}

*Statistically significant difference

Table $\mathbf{V}$ - Comparison between the percentage changes of the different movements of the MRM (mm) of ADDwR cases of G1 and $\mathrm{G} 2$

\begin{tabular}{|ccccc|}
\hline Movement & \multicolumn{2}{c}{ Percentage change $\%$} & \multicolumn{2}{c|}{ Student's $\boldsymbol{t}$ test } \\
& ARS & $\begin{array}{c}\text { Arthrocen- } \\
\text { tesis }\end{array}$ & $\boldsymbol{t}$ & $\mathbf{P}$ \\
\hline Free Pain opening & 29.28 & 8.71 & 5.68 & $\mathrm{p}<0.00001^{\star}$ \\
\hline Maximum unassisted opening & 28.73 & 9.57 & 6.40 & $\mathrm{p}<0.00001^{*}$ \\
\hline Maximum assisted opening & 30.77 & 11.06 & 5.82 & $\mathrm{p}<0.00001^{\star}$ \\
\hline Right Lateral & 76.77 & 51.50 & 1.73 & 0.005 \\
\hline Left Lateral & 83.01 & 37.89 & 1.85 & 0.037 \\
\hline Protrusive & 121.30 & 91.76 & 1.377 & 0.887 \\
\hline
\end{tabular}

*Statistically significant difference

\section{DISCUSSION}

For this study, a convenient sample was selected over a period of two year to study the effectiveness of using of arthrocentesis and insertion of ARS on the MRM of unilateral ADDwR cases. Most subjects who participated in this study were females, which reflects the higher prevalence of TMD in women (75-80\%) compared to men [4]. The percentage change was calculated to overcome any differences between the two groups at the base line.

The evaluation of the measurement of MRM was not only limited to the commonly assessed maximum mouth opening, but also included left and right lateral and protrusive movements as well. The results of this study demonstrated a significant marked improvement for the different movements of the MRM after the treatment of each group ( $p \leq 0.05$ ). That said, there were significant differences between ADDwR subjects of arthrocentesis group and ARS group in the mean changes and percentage changes of most movements of MRM ( $\mathrm{p} \leq$ 0.05). Therefore, the null hypothesis, denoting that there are no differences between the effectiveness of the arthrocentesis and insertion of ARS on improving the different MRM movements in cases of ADDwR, was rejected.

The averages mouth opening of normal subjects ranges from 53 to $58 \mathrm{~mm}$ [22]. In the present study, the mean pain free opening at baseline (T1), for ADDwR subjects of arthrocentesis group and ARS group was 38.50 $\pm 4.85 \mathrm{~mm}$ and $33.61 \pm 1.97 \mathrm{~mm}$, respectively, with marked improvements after treatment to $41.83 \pm 5.25$ and $43.55 \pm 6.4$ (for both groups). These results agree with Kurt et al [3] who recorded a maximum pain free opening for DDwR subjects of $36.56 \pm 10.14 \mathrm{~mm}$ to 39.7 \pm 9.15 and reported marked improvement after using ARS from $38.8 \pm 9.97 \mathrm{~mm}$ to $43.45 \pm$ $10.42 \mathrm{~mm}$.

The results of this study revealed that our baseline assessment is at odds with Celić et al. [24] and Svechtarov et al. [32], who studied the MRM in normal and DDwR subjects. They reported that the mean mouth opening for DDwR subjects was larger than the current study (47.0 $\pm 5.1 \mathrm{~mm}$ and $46.0 \pm 5.05 \mathrm{~mm}$ respectively). Similarly, the average baseline right and left lateral movement of DDwR subjects was lower 
than that reported in other studies [19]. In this study, a mean right lateral movement of $6.55 \pm$ $1.94 \mathrm{~mm}$ (G1) and $6.61 \pm 2.90 \mathrm{~mm}$ (G2) was recorded, and a mean left lateral movement of were $6.55 \pm 1.50$ (G1) $\mathrm{mm}$ and $5.66 \pm 2.17$ $\mathrm{mm}$ (G2). The average reported right lateral movement was $8.0 \pm 2.7 \mathrm{~mm}$, and the average of left lateral was $8.2 \pm 2.7 \mathrm{~mm}$ in DDwR subjects $[22,23]$. Also, the average protrusive movement for ADDwR subjects of was $1.88 \pm 0.76$ for G1 $\mathrm{mm}$ and $1.77 \pm 0.73 \mathrm{~mm}$ for $\mathrm{G} 2$, which is significantly limited compared to healthy subjects, who have a 6.16-7.91 $\mathrm{mm}[22,31]$ and is also significantly restricted compared to other studies evaluating the protrusive movements in ADDwR patients[10,23]. In general, this study corroborates the results of other studies demonstrating the limitations of MRM in ADDwR subjects [13,22,23].

The results of the present study revealed that the ARS have a more superior effect on the different movements of the MRM in ADDwR cases, when compared to arthrocentesis (Table 5). This may be attributed to the forward position of the mandible that is achieved by using ARS, which may in turn decrease the overload on the retrodiscal tissues, allowing adaptive changes to occur [24]. Moreover, there were no side effects observed in the group treated with ARS after 6 months in the current study. While other studies support the use of arthrocentesis [21,25] they were not able to statistically confirm that arthrocentesis was more effective than splint therapy in eliminating the limitation of jaw movement this impression [22]. Therefore, nonsurgical splint therapy should be considered as a first line of treatment to prevent the postoperative surgical complications that may be encountered after its application, particularly given its lower cost and lower risk [23]. The differences in outcome of this study with others $[15,16]$ might be attributed to the patient population, sample size, and treatment conditions.
Although both arthrocentesis and ARS had significant improvement effects on the different movements of the MRM of ADDwR cases, these improvements do not necessarily mean that the disorder is cured [24]. Further studies are needed to evaluate the effectiveness of using the arthrocentesis and ARS in treatment of ADDwR cases on the long-term.

\section{CONCLUSION}

Within the limitations of this study, the use of anterior repositioning splint is recommended as non-invasive method for improving the mandibular range of motion in the management of temporomandibular joint anterior disc displacement with reduction cases. Further studies are needed to confirm these findings the stability of the results on the long-term.

\section{Funding}

No funding agency provided a significant amount of money in support of this research.

\section{Disclosure statement}

The authors have stated explicitly that there are no conflicts of interest in connection with this article.

\section{Data Availability statement:}

Data will provide by the corresponding author upon reasonable request.

\section{REFERENCES}

1. Carrara SV, Conti PCR, Barbosa JS. Statement of the 1st consensus on temporomandibular disorders and orofacial pain. Dental Press J Orthod. 2010;15(3):114-20.doi: 10.1590/S2176-94512010000300014

2. Young AL. Internal derangements of the temporomandibular joint: a review of the anatomy, diagnosis, and management. J Indian Prosthodont Soc. 2015 Jan-Mar;15(1):2-7. doi: 10.4103/0972-4052.156998

3. Kurt H, Emre Mumcu E, Tonguç Sülün T, DiraçoGLu D, Ünalan F, Aksoy C, et al. Comparison of effectiveness of stabilization splint, anterior repositioning splint and behavioral therapy in treatment of disc displacement with reduction. Turk J Phys Med Rehab. 2011;57:25-30. doi: 10.4274/tftr.57.05

4. Warren MP,Fried JL. Temporomandibular disorders and hormones in women. Cells Tissues Organs. 2001;169:187-92. doi: 10.1159/000047881 
5. Chow RL, Lee PK. Overview and update on treatment of common temporomandibular joint disorders. Dent Bulletin 2009;14:5-8.

6. Okeson's JP. Management of temporomandibular disorders and occlusion. 6th ed. St.Louis: Mosby;2003.

7. Dolwick MF, Katzberg RW, Helms CA. Internal derangements of the temporomandibular joint: fact or fiction? J Prosthet Dent. 1983 Mar;49(3):415-8. doi: 10.1016/0022-3913(83)90287-1

8. Kurita K, Westesson PL, Yuasa H, Toyama M, Machida J, Ogi N. Natural course of untreated symptomatic temporomandibular joint disc displacement without reduction. J Dent Res. 1998 Feb;77(2):361-5. doi: 10.1177/00220345980770020401

9. Manfredini D, Chiappe G, Bosco M. Research diagnostic criteria for temporomandibular disorders (RDC/TMD) axis I diagnoses in an Italian patient population. J Oral Rehabil. 2006 Aug;33(8):551-8. doi: 10.1111/j:13652842.2006.01600.x

10. Yang C, Cai XY, Chen MJ, Zhang SY. New arthroscopic disc repositioning and suturing technique for treating an anteriorly displaced disc of the temporomandibular joint: part I--technique introduction. Int J Oral Maxillofac Surg.2012 Sep;41(9):1058-63. doi:10.1016/j.jjom.2012.05.025

11. Diraçoğlu D, Saral IB, Keklik B, Kurt H, Emekli U, Ozçakar L, et al. Arthrocentesis versus nonsurgical methods in the treatment of temporomandibular disc displacement without reduction. Oral Surg Oral Med Oral Pathol Oral Radiol Endod. 2009 Jul;108(1):3-8. doi:10.1016/j. triple0.2009.01.005

12. Schiffman E, Ohrbach R, Truelove E, Look J, Anderson G, Goulet JP, et al. Diagnostic criteria for temporomandibular disorders (DC/TMD) for clinical and research applications: recommendations of the International RDC/TMD Consortium Network* and Orofacial Pain Special Interest Groupt. J Oral Facial Pain Headache. 2014 Winter;28(1):6-27. doi: 10.11607/jop.1151

13. Barkin S, Weinberg S. Internal derangements of the temporomandibular joint: the role of arthroscopic surgery and arthrocentesis. J Can Dent Assoc. 2000 Apr;66(4):199-203

14. Gauer RL, Semidey MJ. Diagnosis and treatment of temporomandibular disorders. Am Fam Physician. 2015 Mar 15;91(6):378-86

15. Huang IY, Wu JH, Kao YH, Chen CM, Chen CM, Yang YH. Splint therapy for disc displacement with reduction of the temporomandibular joint. part l: modified mandibular splint therapy. Kaohsiung J Med Sci. 2011 Aug;27(8):323-9. doi: 10.1016/j.kjms.2011.03.006

16. Bauer W, Augthun M, Wehrbein H, Muller-Leisse C, Diedrich E. Occlusal splint therapy in reciprocal TMJ clicking: a critical observation within a follow-up study. Fortchritte der Kieferorthopaedie 1993;54(3):108-18. doi:10.1007/ bf02409020

17. Orenstein ES. Anterior repositioning appliances when used for anterior disk displacement with reduction--a critical review. Cranio. 1993 Apr;11(2):141-5. doi:10.1080/08869634.1993.11677955

18. Al-Baghdadi M, Durham J, Araujo-Soares V, Robalino S, Errington L, Steele J. TMJ Disc Displacement without Reduction Management: A Systematic Review. J Dent Res. 2014 Jul;93(7 Suppl):37S-51S. doi: $10.1177 / 0022034514528333$
19. Dao TT, Lavigne GJ, Charbonneau A, Feine JS, Lund JP. The efficacy of oral splints in the treatment of myofascial pain of the jaw muscles: a controlled clinical trial. Pain. 1994 Jan;56(1):85-94. doi: 10.1016/0304-3959(94)90153-8

20. Alpaslan C, Kahraman S, Güner B, Cula S. Does the use of soft or hard splints affect the short-term outcome of temporomandibular joint arthrocentesis? Int J Oral Maxillofac Surg. 2008 May;37(5):424-7. doi: 10.1016/j.jom.2008.01.022

21. Alpaslan C, Dolwick MF, Heft MW. Five-year retrospective evaluation of temporomandibular joint arthrocentesis. Int J Oral Maxillofac Surg. 2003 Jun;32(3):263-7. doi: 10.1054/ijom.2003.0371

22. Ingawalé S, Goswami T. Temporomandibular joint: disorders, treatments, and biomechanics. Ann Biomed Eng. 2009 May;37(5):976-96. doi: 10.1007/ s10439-009-9659-4

23. Ingervall B. Variation of the range of movement of the mandible in relation to facial morphology in young adults. Scand J Dent Res. 1971;79(2):133-40. doi: 10.1111/.j.1600-0722.1971.tb02003.x

24. Celić R, Jerolimov V, Knezović Zlatarić D, Klaić B. Measurement of mandibular movements in patients with temporomandibular disorders and in asymptomatic subjects. Coll Antropol. 2003;27 Suppl 2:43-9.

25. Madani AS, Mirmortazavi A. Comparison of three treatment options for painful temporomandibular joint clicking. J Oral Sci. 2011 Sep;53(3):349-54. doi:10.2334/josnusd.53.349

26. Yucel MA, Gozneli R, Alkumru HN, Kulak-Ozkan Y. Evaluating the additional effects of arthrocentesis on the condylar pathways of temporomandibular joint in patients with internal derangement treated with stabilizing splint. J Craniomaxillofac Surg. 2014 Jul;42(5):e86-90. doi: 10.1016/j.jcms.2013.07.002

27. Conti PC, Miranda JE, Conti AC, Pegoraro LF, Araújo Cdos R. Partial time use of anterior repositioning splints in the management of TMJ pain and dysfunction: a one-year controlled study. J Appl Oral Sci. 2005 Dec;13(4):34550. doi:10.1590/s1678-77572005000400006

28. Carmeli E, Sheklow SL, Bloomenfeld I. Comparative study of repositioning splint therapy and passive manual range of motion techniques for anterior displaced temporomandibular discs with unstable excursive reduction. Physiotherapy 2001;87(1):26-36. doi: 101016/S0031-9406(05)61189-3

29. Diraçoğlu D, Saral IB, Keklik B, KurtH, Emekli U, Ozçakar L, etal. Arthrocentesis versus nonsurgical methods inthe treatment of temporomandibular disc displacement without reduction. Oral Surg Oral Med Oral Pathol Oral Radiol Endod 2009;108(1):3-8. doi:10.1016/j. tripleo.2009.01.005

30. Eberhard D, Bantleon HP, Steger W. The efficacy of anterior repositioning splint therapy studied by magnetic resonance imaging. Eur J Orthod. 2002 Aug;24(4):343-52. doi: 10.1093/ejo/24.4.343

31. Muhtarogullari M, Avci M, Yuzugullu B. Efficiency of pivot splints as jaw exercise apparatus in combination with stabilization splints in anterior disc displacement without reduction: a retrospective study. Head Face Med. 2014 Oct 9;10:42. doi: 10.1186/1746-160X-10-42.

32. Svechtarov V, Hristova M, Nencheva-Svechtarova S, Tonchev T. Mandibular range of motion and its relation to tempromandibular disorders. Script Scienc Med Dent. 2015;1(1):21-6.

Prof. Dr. Mohamed Helal (Corresponding address)

Al-Azhar University, Faculty of Dentistry, Department of Removable Prosthodontics, Cairo, Egypt.

Email: mhelal@azhar.edu.eg

Date submitted: 2020 Mar 09

Accept submission: 2020 Sep 15 